University of Wollongong

Research Online

Faculty of Social Sciences - Papers (Archive) Faculty of Arts, Social Sciences \& Humanities

2014

Promoting awareness, knowledge of and compliance with the National Children's Physical Activity Guidelines

Lyn Phillipson

University of Wollongong, Iphillip@uow.edu.au

Danika Hall

University of Wollongong, danika@uow.edu.au

Anthony D. Okely

University of Wollongong, tokely@uow.edu.au

Sandra C. Jones

University of Wollongong, sandraj@uow.edu.au

Dylan Cliff

University of Wollongong, dylanc@uow.edu.au

See next page for additional authors

Follow this and additional works at: https://ro.uow.edu.au/sspapers

Part of the Education Commons, and the Social and Behavioral Sciences Commons

Research Online is the open access institutional repository for the University of Wollongong. For further information contact the UOW Library: research-pubs@uow.edu.au 


\title{
Promoting awareness, knowledge of and compliance with the National Children's Physical Activity Guidelines
}

\author{
Abstract \\ Abstract presented at be active 2014, 15-18 October 2014, National Convention Centre, Australian Capital \\ Territory, Australia \\ Keywords \\ compliance, knowledge, guidelines, awareness, activity, children, promoting, physical, national \\ Disciplines \\ Education | Social and Behavioral Sciences

\section{Publication Details} \\ Phillipson, L., Hall, D., Okely, T., Jones, S., Cliff, D., Lee, J. K., Vella, S., Chapman, M., Franco, L. \& Kirk- \\ Downey, T. (2014). Promoting awareness, knowledge of and compliance with the National Children's \\ Physical Activity Guidelines. Journal of Science and Medicine in Sport, 18 (Supplement 1), 162.

\section{Authors} \\ Lyn Phillipson, Danika Hall, Anthony D. Okely, Sandra C. Jones, Dylan Cliff, Jeong Kyu Lee, Stewart Vella, M \\ Chapman, Lisa Franco, and T Kirk-Downey
}




\title{
Promoting awareness, knowledge of and compliance with the National Children's Physical Activity Guidelines
}

\author{
L. Phillipson ${ }^{1}$, D. Hall ${ }^{1}$, T. Okely ${ }^{2}$, S. Jones ${ }^{1}$, D. Cliff ${ }^{2}$, J.K. Lee ${ }^{1}$, S. Vella ${ }^{2}$, M. Chapman ${ }^{1}$, L. Franco ${ }^{3}$, \\ T. Kirk-Downey ${ }^{4}$ \\ ${ }^{1}$ Centre For Health Initiatives, University of Wollongong, Australia \\ ${ }^{2}$ Early Start Research Institute, University of Wollongong, Australia \\ ${ }^{3}$ Health Promotion Unit, Illawarra Shoalhaven Local Health District, Australia \\ ${ }^{4}$ Child \& Family Services, Wollongong City Council, Australia
}

Introduction: In Australia, public awareness of the physical activity (PA) guidelines for children is disturbingly low. This is one contributor to the fact that only $20 \%$ of school-aged children are sufficiently active and meet the recommended $\geq 60 \mathrm{~min} /$ day of moderate-tovigorous physical activity. The release of the revised Australian Physical Activity Guidelines for Children (5-12 years) in February 2014 prompted the need for a different approach to actively engage children and parents to improve knowledge, attitudes and uptake of the new guidelines to improve child health and wellbeing.

Methods: A multi-component social marketing intervention to promote the PA guidelines was conducted in three pilot schools in a metropolitan city, informed by qualitative research with children, parents and teachers. The intervention promoted key benefits of PA (social and fun) and overcame target audiences' perceived barriers to uptake of the guidelines (inconvenient, expensive and difficult). Nine before-school events were held in three public schools, with up to 230 children at each event engaged in active games. Children took home active toys with tailored active homework and printed information for parents. The PA guidelines were also promoted at a community level via a radio advertisement, a website (www.activeeveryday.org.au), posters, brochures, and postcards distributed to community organisations. The school intervention was evaluated using a pre-post survey of parents at participating schools.

Results: Analysis of matched pre/post survey responses $(n=79)$ found significant increases ( $p<0.05$ ) in: parent awareness of the guidelines (from $24 \%$ to $59 \%$ ), knowledge of guideline content (from $45 \%$ to $76 \%$ ), mean scores for reported encouragement of their child to try a new physical activity (from 3.6 to 3.9); and decreases in mean scores for belief that being active for 60 min every day is difficult for children to achieve (from 2.5 to 2.2). Finally there was an overall increase in the mean number of days parents reported their child participated in at least 60min of physical activity (over the past seven days) from 4.3 to 4.7. Discussion: The social marketing approach proved useful to select and research target audiences and to understand their perceived benefits of, and barriers/competition to, achieving the PA guidelines. The current pilot was successful in moving knowledge and experience of the PA guidelines from the school into the home (e.g. use of toys, trying of new skills, use of active homework) and into the practice of teachers (e.g. prescription of PA homework). 